\title{
Protein expression in dairy cows with and without subclinical hypocalcaemia
}

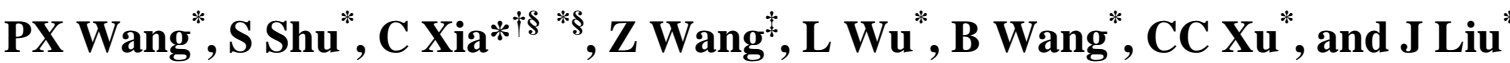

${ }^{*}$ College of Animal Science and Veterinary Medicine, Heilongjiang Bayi Agricultural University, Daqing 163319, China.

† Synergetic Innovation Center of Food Safety and Nutrition, Northeast Agricultural University, Harbin, 150030, China.

$\ddagger$ College of Animal Science and Veterinary Medicine, Jilin University, Chang Chun 130062, China.

$\checkmark$ Corresponding Author: E-mail: xcwlxyf@sohu.com

Supplementary Figure 1. (A) and (B) Representative output traces of the relative intensity at different mass to charge $(\mathrm{m} / \mathrm{z})$ ratios identified using Surface-enhanced laser desorption/ionization time-offlight mass spectrometry (SELDI-TOF-MS), for plasma samples from dairy cows with (T) or without (C) subclinical hypocalcaemia. (C) Gel view of the greatest significant differences between the peaks of the cows with (T) or without (C) subclinical hypocalcaemia.

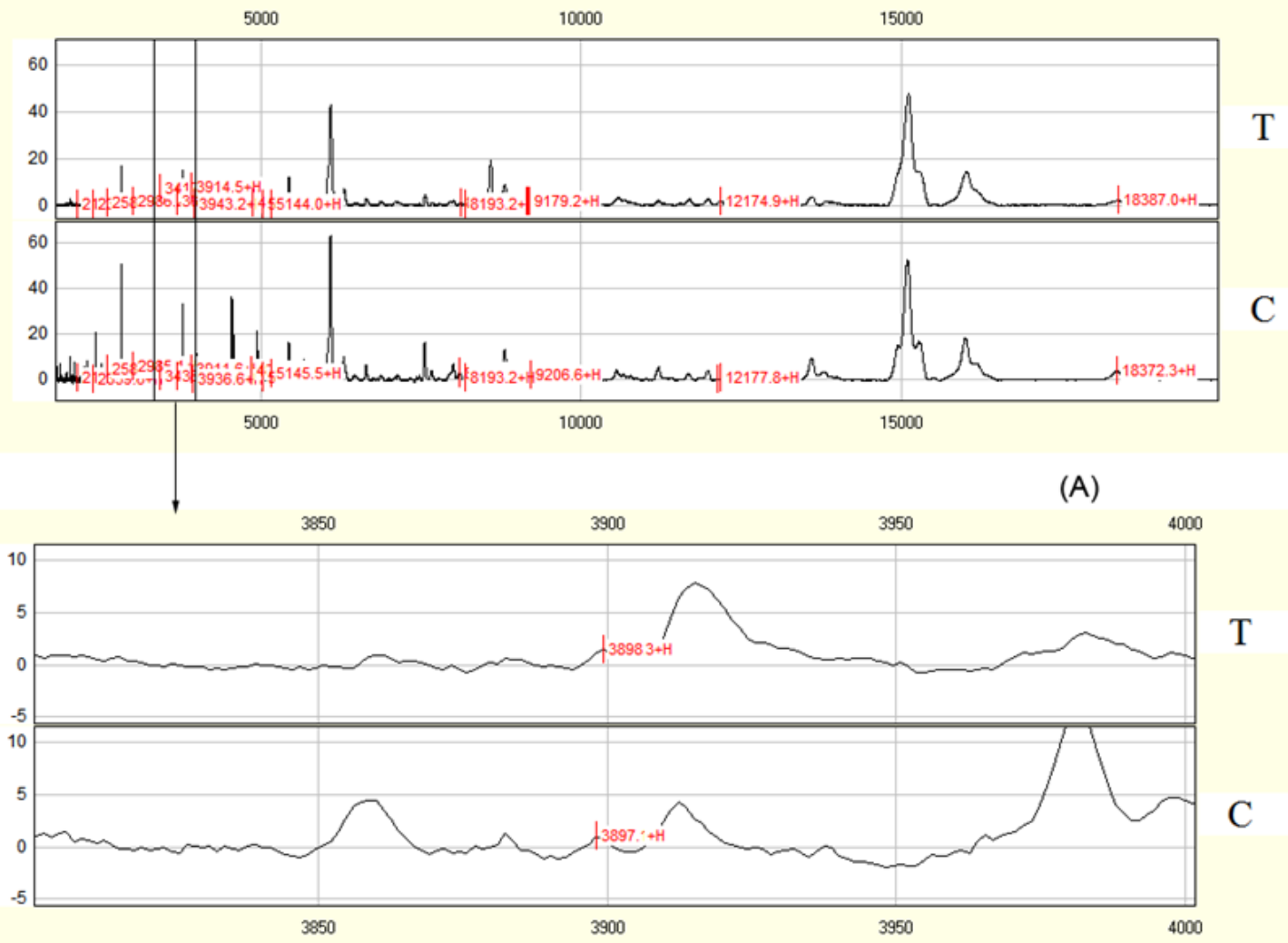

(B)

3850

3900

3950

4000

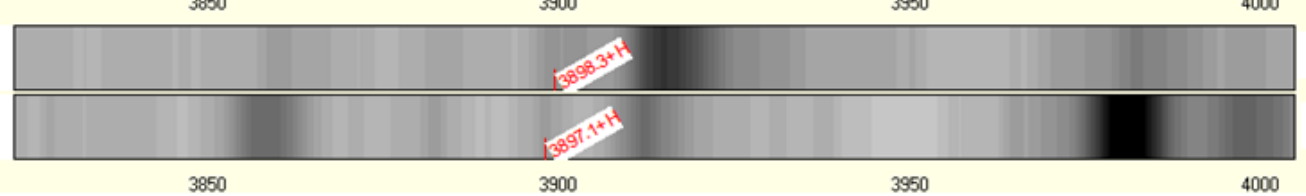

$\mathrm{T}$

$\mathrm{C}$

(C)

The content of this supplementary information has not been edited. All risk and liability rest with the authors. 